\title{
Effect of Family Climate on Internet Addiction among College Students of Bathinda District
}

\author{
Gupta, $S^{1 *}$, Singh, $B^{2}$
}

\section{ABSTRACT}

Internet is a worldwide, decentralized network of hundreds and thousands of computers linked to each other through satellites orbiting in the space. Presently internet is not only limited to computers but also includes millions of people who are connected to each other through the internet. It has emerged as a major source of communication. On the one hand it has helped lets millions of people to express themselves and communicate with people separated by millions of kilometers; on the other hand it makes people dependent. The advent of computers has given birth to a new form of addiction called internet addiction. The symptoms of internet addiction not only resemble the symptoms substance addiction but also are equally harmful. The severity of internet addiction has made American Psychological Association include it into the appendices of DSM-V. Lot of research has been initiated to see the variables playing a vital role in the development of internet addiction. As the family is the most significant unit in every individual's life, so the present study aims to see the relationship between family climate and internet addiction.

Keywords: Internet, Internet Addiction, Family Climate, Relationship.

The advent of computers has revolutionized every sphere of life. The one invention which has influenced maximum impact is internet. It is the connection between computer terminals at different places through satellite. In the beginning it amazed everybody with the lightning speed with which e-mails could be sent across the globe. Slowly its use became more and more widespread for transmitting information, online shopping, sharing knowledge, research, paying bills etc. Presently the use of internet has become an inseparable part of almost everybody's life. The ease of access of internet through smart phones made it even more convenient and useful at the same time. The smart phones with user friendly interface and applications made instant messaging cheap and easy. As excess of everything is bad, so the ease of availability and long term use of internet has lead to the problem of addiction. Internet addiction disorder (IAD) was originally proposed as a mental disorder in a satirical hoax by Ivan Goldberg in 1995 (Eppright, Allwood, Stern, \& Theiss, 1999) (Garrison \& Long, 1995). Internet addiction as it has been termed is as serious a matter of concern as substance abuse. The seriousness of the problem has

\footnotetext{
${ }^{1}$ Assistant Professor, Department of Psychology, Government Rajindra College, Bathinda

${ }^{2}$ Assistant Professor, Department of Psychology, Desh Bhagat University, Mandi Gobindgarh *Corresponding Author

(C) 2015 I S Gupta, B Singh; licensee IJIP. This is an Open Access Research distributed under the terms of the Creative Commons Attribution License (http://creativecommons.org/licenses/by/2.0), which permits unrestricted use, distribution, and reproduction in any Medium, provided the original work is properly cited.
} 


\section{Effect of Family Climate on Internet Addiction among College Students of Bathinda District}

made APA include internet addiction in the appendices of DSM-V. Lot of research has been carried out to see the effects of internet addiction on human cognitions and social life. Research has found that internet addiction is related with many physical, social and psychological problems. The first research on internet addiction was done by Young, 1996 which was published in APA. Internet addiction commonly refers to one's inability to control his or her urge to be on-line, resulting in uncontrolled use of the Internet and adverse consequences in life, such as marked distress, impaired social interaction and loss of educational/occupational interests (Aboujaoude, 2010) (Douglas, et al., 2008) (Kuss, Griffiths, Karila, \& Billeux, 2013). IAD, or pathological Internet use, may be caused by a spectrum of on-line activities including gaming, shopping, gambling, viewing pornography, and social networking. Clinical studies have demonstrated that subjects with uncontrolled use of the Internet, not only share core symptoms with substance addiction such as tolerance, withdrawal symptoms and relapse (Beard \& Wolf, 2001) (Young, 1998), but also frequently have psychiatric co-morbidity, including attention deficit/hyperactivity disorder, anxiety disorders, sleep disorders, and obsessive-compulsiveness (Bernardi \& Pallanti, 2009) (Ko, Yen, Yen, Chen, \& Chen, 2012) (Yen, Ko, Yen, Wu, \& Yang, 2007). Internet addiction just implies the extent to which the normal lives i.e. work; study etc. is affected by the use of internet (Fitzpatrick, 2008). Internet Addiction is a global problem that transcends culture, race, age and gender. Internet has many uses ranging from surfing the net for books, general knowledge, and current affairs to paying bills. The online tasks which can be addictive include gaming, social sites, gambling, media etc. Internet addiction can lead to mental problems like lack of social engagement, health issues like cervical, back ache, insomnia and lack of interest in outdoor activities (Saisan, Smith, Robinson, \& Segal, 2013). Internet addiction can lead to problem as severe as damage to brain of adolescents and young adults (Waugn, 2012).

Research on internet addiction began in 1996 and the conclusions were reported at the American Psychological Association. Over 600 cases showing clinical signs of internet addiction were measured through DSM-IV criteria for Pathological Gambling adaptation (Young, 1998). In the beginning, many attempts were made to define Internet addiction and how did it differ from normal internet usage. The earliest effort to diagnose internet addiction focused on amount of time spent online. Anyone spending 40 to 80 hours online for recreational or private use was considered addicted (Young, 1998). It was found that long and continuous use of internet affects sleep patterns, increases fatigue, tiredness and lead to increased consumption of coffee, tea, etc. In India limited numbers of studies have been done to estimate the problem of internet addiction. A study done by Kanwal Nalwa and Archana Preet Anand of Punjabi University of India studied Internet addiction in school children from age 16 to 18 years. They identified two groups of internet users - dependents and non-dependents. Dependents are those who delay other work to spend time on the internet, they sleep less as they are online till late at night and feel that life without internet will be boring. Dependents were online for more time and so were high on loneliness than the non-dependents (Nalwa, K.\& Anand, A., 2003). 
Research has shown that internet addiction has adverse effects on long term internet users. Now the question arises that what are the different reasons for being online for long duration of time? As family is the most prominent institute of any individual's family, so it is important to know the relationship between internet addiction and family climate. The aim of the present study is to measure the correlation between family climate and internet addiction.

\section{METHODOLOGY}

For the present study family climate was measured using Family Climate Scale by Dr. Beena Shah. Family climate was assessed on 10 dimensions which included Restrictiveness vs. Freedom, Indulgence vs. Avoidance, Partiality vs. Fairness, Attention vs. Negligence, Acceptance vs. Rejection, Warmth vs. Cold Relations, Trust vs. Distrust, Dominance vs. Submissiveness, Expectation vs. Hopeless, and Open communication vs. controlled communication.

Internet Addiction was measured using Internet Addiction Test (IAT) by Young. The test measures the client's involvement with the computer and classifies the addictive behavior in three categories- mild, moderate and severe impairment. As the IAT has been translated into many languages; so it is also called a global measure. It consists of 20-items based on five-point Likert scale. Higher the score more is internet addiction.

On the basis of the thorough study of the variables and considering the previous research efforts, the present study aims to test the hypothesis that "It is expected that there is a negative correlation between family climate and internet addiction.”

\section{RESULTS}

The results show that there is a significant negative correlation between family climate and internet addiction. The value of Pearson's product moment correlation comes out to be -0.284 which is significant at alpha $=0.01$. This shows that there is a highly significant correlation between the kind of family climate and internet addiction. The correlation is negative which implies that more the value of family climate lesser will be the value of internet addiction. In other words, better the family climate lesser will be the chances of internet addiction. Table no. 1 shows the values of correlation between the two variables. 
Table no. 1 Showing Correlation between Family Climate and Internet Addiction (N=100)

\begin{tabular}{|c|c|}
\hline Variables & Value of Correlation \\
\hline & \\
\hline Family Climate and Internet Addiction & $-0.284^{* *}$ \\
\hline
\end{tabular}

** Correlation is significant at the 0.01 level (2-tailed).

\section{DISCUSSION}

The aim of the present study was to know the relationship between family climate and internet addiction. For this purpose a sample of 100 college students was taken. They were administered Family climate scale by Dr. Beena Shah and Internet Addiction Test by Young. The Pearson's' Product Moment correlation was calculated. The results reflected that there is a highly significant negative correlation between family climate and internet addiction. The family is the foundation stone of every person's personality and behavior. If the family climate is conducive then the youth are less likely to develop addiction to internet. This result supports our hypothesis which stated that there is a negative correlation between family climate and internet addiction. As the results are highly significant so the null hypothesis stating that there is no correlation between the two variables is rejected and the alternate hypothesis stating that there is a negative correlation between the two variables is accepted.

These results are in accordance with many different studies conducted in different places from time to time. In a study it was found that the subjects who used internet for longer time had lesser interactions with the family (Kraut, Patterson, Lundmark, Kiesler, Mukopadhyay, \& Scherlis, 1998). Another study by Nie and Hillygus (2002) through cross-sectional time diary study, found that the more the use of Internet, lesser was the interaction with family members. Young and Rogers, 1997 found that the addicted internet users used Internet as an escape. Another research found that out of the many potent reasons for addiction dysfunctional families, is one of the important reason (Ko C.-H. , Yen, Yen, Lin, \& Yang, 2007). Many studies have concluded that the youth uses internet to overcome feelings of depression, social phobia, feelings of guilt, and family discords etc. (Beard, Internet addiction in children and adolescents., 2008) (Jang, Hwang, \& Choi, 2008) (Morahan-Martin, 1999) (Young K. , What makes the Internet addictive: Potential explanations for pathological Internet use., 1997) (Young, 1998a). The individuals from families with conflicts and poor communication are more prone to using internet for longer time to avoid the conflicts and get support (Beard, 2008) (Yen, Ko, Yen, Wu, \& Yang, 2007) (Young, 2009). It has also been found that the adolescents from families with substance abuse have more chances 
of developing internet addiction (Yen, Ko, Yen, Wu, \& Yang, 2007) (Young, 2009). In this way the aim behind being online for long duration of time may be to escape the stress of family environment and a mechanism of coping easily available (Beard, 2008) (Eastin, 2005).

The above discussion reflects that the family environment is an important variable in the development of internet addiction. Though most of these studies were done in foreign nations but with the spread of internet and increasing use of smart phones, internet addiction is increasing in India also. The recent case of couple who developed profound depression due to chatting on instant messaging application for 15-18 hours daily served as a eye opener. Considering the relationship between family climate and internet addiction it is important that the society should aim at providing a cooperative family environment and good parent child relationships in order to handle the emerging problem of internet addiction. For the individuals already addicted to the internet or on the borderline of developing internet addiction, appropriate steps should be taken to make the family environment healthy.

In the end, it can be concluded that though internet addiction is a new disorder, it is as harmful as substance abuse. The ease of access of internet may lead to the spread of disorder at an equally fast pace. So, steps should be taken to prevent it and efforts should be made to develop good habits among the youth by providing a healthy family environment.

\section{WORKS CITED}

Aboujaoude, E. (2010). Problematic internet use: an overview. World Psychiatry, 9, 85-90.

Beard, K. (2008). Internet addiction in children and adolescents. In C. B. Yarnall (Ed.), Computer science research trends (pp. 59-70). Hauppauge, New York: Nova Science.

Beard, K., \& Wolf, E. (2001). Modification in the proposed diagnostic criteria for Internet addiction. CyberPsychology \& Behavior , 4, 377-383.

Bernardi, S., \& Pallanti, S. (2009). Internet addiction: a descriptive clinical study focusing on comorbidities and dissociative symptoms. Comprehensive Psychiatry , 50 (6), 510-516.

Douglas, A. M., Stepchenkova, S., Byun, S., Ruffini, C., Lee, S., Loutfi, J., et al. (2008). Internet addiction: meta-synthesis of qualitative research for the decade 1996-2006. Computer in Human Behavior , 24, 3027-3044.

Eastin, M. (2005). Teen Internet use: Realating social perceptions and cognitive models to behavior. CyberPsychology and Behavior , 8, 62-75.

Eppright, T., Allwood, M., Stern, B., \& Theiss, T. (1999). Internet addiction: a new type of addiction? Missouri Medicine , 96, 133-136.

Fitzpatrick, J. (2008). Internet Addiction: Recognition and Interventions. Retrieved from Armenian Medical Network: www.health.am/psy/more/internet-addiction-recognitionand-interventions

Garrison, J., \& Long, P. (1995). Getting off the superhighway. Health , 9, 20-22. 


\section{Effect of Family Climate on Internet Addiction among College Students of Bathinda District}

Jang, K., Hwang, S. Y., \& Choi, J. Y. (2008). Internet addiction and psychiatric symptoms among Korean adolescents. Journal of School Health (78), 165-171.

Ko, C., Yen, J., Yen, C., Chen, C., \& Chen, C. (2012). The association between internet addiction and psychiatric disorder: a review of the literature. European Psychiatry , 27, 1-8.

Ko, C.-H., Yen, J.-Y., Yen, C.-F., Lin, H.-C., \& Yang, M.-J. (2007). Factors Predictive for Incidence and Remission of Internet Addiction in Young Adolescents: A Prospective Study. CyberPsychology \& Behavior , 10 (4), 545-551. doi:10.1089/cpb.2007.9992.

Kraut, R., Patterson, M., Lundmark, V., Kiesler, S., Mukopadhyay, T., \& Scherlis, W. (1998). Internet paradox: A social technology that reduces social involvement and psychological well-being? American Psychologist (53), 1017-1031.

Kuss, D., Griffiths, M., Karila, L., \& Billeux, J. (2013). Internet addiction: a systematic review of epidemiological research for the last decade. Current Pharmaceutical Design , 4026-52.

Morahan-Martin, J. (1999). The relationship between loneliness and internet use and abuse. CyberPsychology \& Behavior , 2, 431-439.

Nalwa, K.\& Anand, A. (2003). Internet addiction in students: A cause of concern. CyberPsychology \& Behavior , 6 (6), 653-656.

Nie, N., \& Hillygus, S. (2002). The impact of Internet use on sociability: time diary findings. IT and Society , 1 (1), 1-20.

Saisan, J., Smith, M., Robinson, L., \& Segal, J. (2013). Internet \& Computer addiction: Signs, Symptoms, and Treatment. Retrieved Feb 19, 2014, from Helpguide.org: http://www.helpguide.org/mental/internet_cybersex_addiction.htm

Waugn, R. (2012). Internet addiction can cause physical damage to the brain, just like drugs, say researchers. Retrieved Feb 20, 2014, from http://www.dailymail.co.uk/sciencetech/article-2085369/Internet-addiction-causephysical-damage-brain-just-like-drugs-say-researchers.html.

Yen, J., Ko, C., Yen, C., Wu, H., \& Yang, M. (2007). The comorbid psychiatric symptoms of internet. Addiction: attention deficit and hyperactivity disorder (ADHD), depression, social phobia, and hostility. Journal of Adolescence Health , 93-98.

Young, K. S. (1998). Internet addiction: the emergence of a new clinical disorder. CyberPsychology \& Behavior , 237-244.

Young, K. S., \& Rogers, R. (1997). The relationship between depression and Internet addiction. CyberPsychology \& Behavior , 25-28.

Young, K. (1998a). The center for online addiciton- Frequently asked questions. Retrieved January 9, 2002, from http://www.netaddiction.com/resources/faq.html.

Young, K. (2009). Understanding online gaming addiction and treatment issues for adolescents. American Journal of Family Therapy, 37, 355-372.

Young, K. (1997). What makes the Internet addictive: Potential explanations for pathological Internet use. Retrieved October 25, 2001, from http://www.netaddiction.com/articles/habbitforming html. 